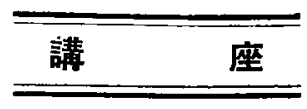

\title{
超 音速翼理 論 の展望
}

\section{1. 序言}

超音速空気力学は最近 10 年䦎に急速の進步を遂げ, 今や空気力学の中でも最子美しい体系の一つを形作る に至った，したがって，一般には非常に新しい学問分 野の上らに考えられているが，その歴史は以外に古 く，有名な J. Ackeret の超音速 2 次元望理論》 は既 に 1925 年に発表されている，それ以後，von Kármán の軸対称物体の抵抗理論2)，H. Schlichting の超音速 3 次元翼理論 ${ }^{3}$ ) A. Busemann の錐場理論 (Conicalfield theory $\left.{ }^{4}\right)$ によって超音速理論の骨格が大体定ま って来たのである. その後ターボ・ジェット抽びロ ヶット・ンジッの進歩発澾による飛行機の速度增大 扣よび超音速我行の可能性は, 空気力学者を非常に刺 战し，最近 10 年間に执いて，上記の骨組にあらゆる 改良拉よび肉付けがなされて現在見るよらな華麗な理 論体系が完成されたので岕る。

本講座の目的性，超音速理論中最もよく完成され， また最す実用的価檤の多い線型翼理論についてその基 碟概念，理論的取扱いの概要，および実験との比較を 述べその有用性を検討することにある.

\section{1. 超音速線型理論}

流体の運動を取扱5場合，考えなければならぬ物理 量は速度の 3 成分, 压力, 密度拉よび温度である.こ れらの末知量に対して次の基焚方程式が与えられる。

(a) Euler の運動方程式

(b) 連続方程式

(c) エネルギー方程式

(d) 状態方程式

流体の粘性括よび熱伝達の影響は境界層および衙撃波 の内部を除いては余り大きくないので，これらを省略 乙，特にその影響の大きい部分劣るいは場合に対して は別筒の取报いをするのか谱通である，粘性执よび䓡 伀達を省略できる場合には，上記の基碟䦎係から，連 綕的な流れに対する微分方程式と，不逨続流与なわち 徵慗波に対する Rankine-Hugoniot の関係を導くこ とができる。

飛行機への応用として空気力学を取扱 万場合, 速度

*東京大学理工学研究䏸
河 村 竜 馬*

が大きくなればなるほど翼厚比の小さい翼，および細 長比の大きい䏱体でけが問題の対象となることは明か である.このよらな物体の運動を取报らが゙り，その 周りの流れの場に特ける括乱は一次の無限小と考える ことができ，基模方程式に执いて二次以上の無限小を 含む項を省略することによって線型微分方程式を得 る. 本問題に括いては，流れの変数として擾乱速度ポ テンシァル $\varphi$ を使らのか便利である. $\varphi$ に対する線 型链分方程式は次の上らになる。

$$
\left(1-M^{2}\right) \frac{\partial^{3} \varphi}{\partial x^{2}}+\frac{\partial^{2} \varphi}{\partial y^{2}}+\frac{\partial^{2} \varphi}{\partial z^{2}}=0
$$

ここで $M$ は一様流の Mach 数であり，一様流の方向 にメ軸をとる。

このような近似においては，区力の楆乱，ナなわち 無限遠方の圧力と，考えている点の圧力との美 $p$ は単 に $x$ 方向の婹乱速度 $u$ にのみ関係乙

$$
p=-\rho_{\infty} U u=-\rho_{\infty} U \varphi_{\varphi_{0}}
$$

で表される、ここで $\rho_{\infty} ， U$ はそれぞれ無限遠方の笜 度扣よび速度である。

また海線の偏角，才なわち速度ら゙ェクトルが $x z$ 面 招よび $x y$ 面との間に作る角度 $\theta_{y}, \theta_{x}$ 㶕単に

$$
\theta_{v}=\frac{v}{U}, \quad \theta_{z}=\frac{w}{U}
$$

と表される. $v ， w$ は蛰乱速度の $y, z$ 成分である. 上記 3 式がここで取扱 5 問題の基碟関係式となる. 特に本論文では超音速すなわち $M>1$ の場合でけを 取报 5 ので，微分方程式は双曲型の波動方程式とな ろ.

綜型微分方程式を導く過程を精密に吟味することに 上って，趋音速線型理論が妥当性を持つための条件を 更に正確に次の上5に表すことができる。

（1）㧸乱速度 $(u, v, w)$ の絶対值は無限遠方の 速度Uおよび音速 $a$ の絶対值に比較して小さくなけれ ばならない。

（2）撘乱速度 $(u, v, w)$ の絶対值は $|U-a| k$ 比較して小さくなければならない。

（1）の制限によってMach 数 $M$ の非常に大きい場 
合は線型理論の範囲から除かれる，この場合にはたと

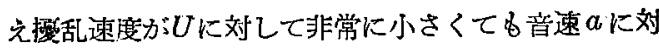
しては必ずしす小さいとはい充なくなるからでする。

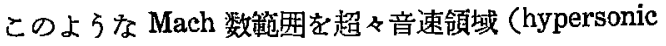
region) とい5. 条件 (2)によって Mach 数が1の 附近もをた線型理論では取报えなくなる。この筑囲を 筤音速領域 (transonic region) とい弓.以上いずれの 場合す基礎方程式柱非線型になり数学的取技力困難に なる。

以上よの5な条件によって弨音速線型理論の活躍乙 得る範囲は一見非常に瘗く制限されるように見元る が，実際には普通の物体，普通の飛行条件に対して $M=1.3 \sim 5$ 程度の範囲でこの理論は十分の実用性を 持っていると考えられる、現在の飛行機力溉に 50 年 の歴史を経てよ 5 や Mach 数䇛囲が $M=0 \sim 1.0$ 程 度で宓ることを思光ば，超音速線型理論の成立ち得る Mach 数範囲力実際の速度に換算する時如何に大きい かが容易にかかり，乙たがって本理論の実際的有用性 の大いさをよく判断することができよう。

音速上上の流れに颃いて，気体が王縮を受ける部分 にはしばしば不連続面すなわち婳撃波が現われること

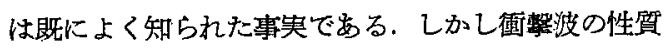
として，それを通っての物理量の変化が小さい場合， 換言すれば，鿉摮波の弱、場合には，その変化はほを んど可这的等 entropy 変化と同等と考元ることがで きる.この意味に扔いて超音速線型理論では，当然唒 踩波の現われる場合にも㣫熬波としての特別の取报い は避けて一つの Mach 波で置換えて考える.乙かしな

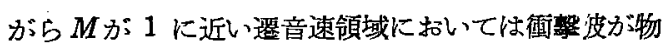
体表面に発生し境界層の制離を惹き括こすため, また 超々音速領域では彴聚波と流れのなす的度が非常に小 さくなり，その結果物体と尖端画撃波との䦌隔に対し て境界層の厚さが必ずしも省略できぬよな状態か現 れるため，この二つの領域ではたと六㣫整波が弱くと るその存在を無視することができなくなる。

\section{2. 超音速流の特性および超音速線型現論の取扱}

流れの Mach 数 $M$ が 1 以下から 1 以上になるに従 って，速度ポテンシャルに関する基砵微分方程式は梢 円型から双曲型へと数学的性質を変光る. 微分方程式 のこのよ弓な㚆化に伴って, 超音速流の特性は亚音速 流とは根本的に異って来る。

今一様流中に置かれた一つの控乱源を考光よろ。 Mach 数が 1 以下の場合は抒乱は音の速さをもってあ らゆる方向に伝わり，究極において全領域がこの㮴乱 源の影響を受ける。これに反し，超音速流の場合に は，擅乱は，揬乱源を頂点とするMach 面によって囲 まれれ内部の領域にナ゙けしが伝わらない，線型理㖮に
际いては，Mach 線住全領域において一様流と Mach 角 $\pm \sin ^{-1}(1 / M)$ の㑇度をなす直線群から成っている 加ら，上記の提乱領域は，椇乱源を頂点とし Mach 角 を半頂角に持ち，軸が一槏流と平行に置かれた円錐の

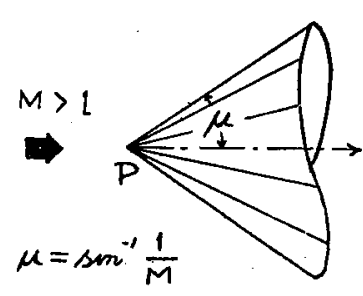

第 1 図 Mach 円錐 中, 下流に搪加るる のの内部になる.こ の Mach 円雓内部の 点は椋乱源 $P$ の影響 を受けるが，Mach 円錐外の点は影響を 受けない(第 1 図).

この現象を逆に考 える時は次のような事が言える，すなわち第2図に招 いて，P点の流れを考える場合には，P点を頂点とし 上流に掂がる Mach 円錐の内部にある楩乱源上りの影

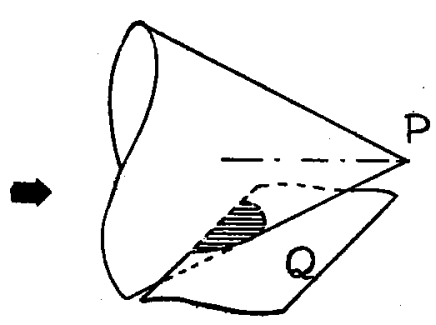

第 2 図 前方 Mach 円錐 響だけを考えれ ばいい, 本論文 ては簡単のた め. 下流に抬る Mach 円錐を単 に Mach 円錐と 呼び，上流に搪 がるものを前方 Mach 四錐と称 して区別することにする，第2図に括いて下方に示し

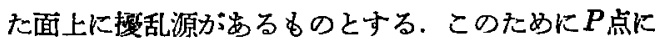
誘導される摄乱を取报ら場合亚音速流では面上すべて の点が $P$ 点に対して影留を持つが; 超音速流では面中、 $P$ 点の前方 Mach 円錐の内部に入る部分，すなわち図 で斜線をほどこした部分の影響だけを考光ればいい。

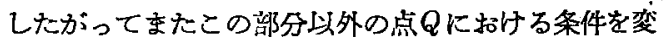
えてもP点の流れには何等の変更をす生じない。

超音速理铪を厚さのない平面的な执からりを持った翼 のよらな物体に適用する場合, その前緑および後緑に 扎いて亜音速の場合とは異った性質か現われて来る. 後退角のない2 次元平板翼が迎角をるって一様流中に 置かれた場合を洘えよう，流れが覀音速の場合，總型 近似に与いては，前縁に然限大の負荷か現われ，揚力 分布は前縁附近では，前縁からの距䗸の $(-1 / 2)$ 乗に 比例することは上く知られた事央である. また後緑に 颃いては，翼の上下面の流れが滑かに後緑を離れなけ ればならないといら有名な Kutta の条件によって, 後縁では場力为雾になる（第 3 図左側）同し翼におい て，一様流の速或方超音速である場合を考えよ5..超 音速の特性として, 翼の影響はこの場合前緑より前方 には放ばない，その結果，前縁では上面には PrandtlMeyer の膨脹波が生じ，下面には酎撃波か現われる。 

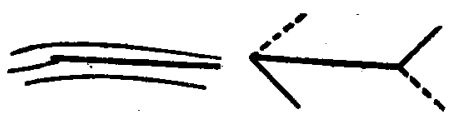

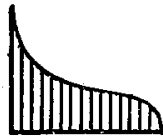

西音速

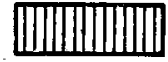

超音速
第3 図 平板翼前後縁に拈ける条件

そして流れは無限大の速度も淝点もいずれす生ずるこ となく翼の上下面に流れ込むことができる。線型理論 では，これらの波はいずれる Mach波をるって置換え られる。この上万な超音速流の特性によって，翼の前 粶の揚力は無限大になることなく有限にとに゙まる。一 方後縁においても，前縁とちょうど逆の現象，すなわ ち上面に重慗波，下面に膨脹波力現われて，流れは滑 かに後緑を離れる，乙たがって Kutta の条件を満す ために負荷か零になる必要はなく，その結果後緑に拉 いてす有限の揚力を発生することができる.第 3 图右 側性超音速の場合の揚力分布である.

前後绿に生ずる以上の上5な特異性は，局部的な流 れの性質によって決定される．流れに対して傾いた前 後縁の場合，之の点の局部的性質を支配するものは一 様流の速度そのるのでなく，前徐縁に対する一様流速 度の直角成分である．この直角成分に関する Mach 数 が1以下か以上かによって上記の性質のいずれをとる か力浃定される。 こ の直角 Mach 数か; 1 以上か 1 以下名は翼 平面を Mach 線に 平行な切線でとりか こむととによって簡 単に決定できる。第 4図に执いて斜線は Mach 線を表す，直 第 4 図超音速的および㩊音 角 Mach 数は $A F$,

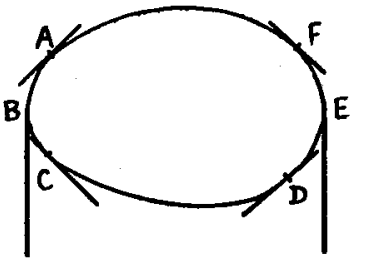
速的前後縁
$C D$ 間では 1 以上, $A C, D F$ 間では 1 以下となる。

この意味で $A F$ を超音速的前緑, $C D$ を超音速的啳 緑， $A B, F E$ を亜音速的前緑， $B C, D E$ を亜音速的 㷋緑之呼心”。

超音速線型理論の基礎方程式は 7頁に示した，この 微分方程式は最む簡単な波野方程式であって数学, 物 理の分野で古くから広く取报われている，乙かし空気 力学上の問題では一般に境界条件が複雜でやっかいな 計算を要することが多い，超音速線型理論で一般的に 使われる方法には次の 3 つがある。
(1) Source, sink, doublet あるいは vortex な どを分布させる方法5。

(2) Laplace 変換を使 5 方法 ${ }^{6}$.

(3) 錐場理論 (conical field theory)i).

これらの方法はそれぞれ独立でなく瓦に変換可能であ る. たとえば(3)の錐場理論は特定の競界条件に対し て(1)からも導く事ができる、また軸対称流に対して 有力な (2)の方法も source ring を考える事によっ て(1)から導くことができる、乙かしそれぞれの方法 は，抢の招のに適した場合に適用ざれた時最も撪力な 力を発揮する。

\section{3. 超音速における抵抗の理論}

第 5 図に招いて原点附近に物体が㧊かれI，II，III は軸が $x$ 軸と平行に置かれた仮想の円筒の 3 つの面を 表するのとする、Iは物体の上流，几は下流にありい

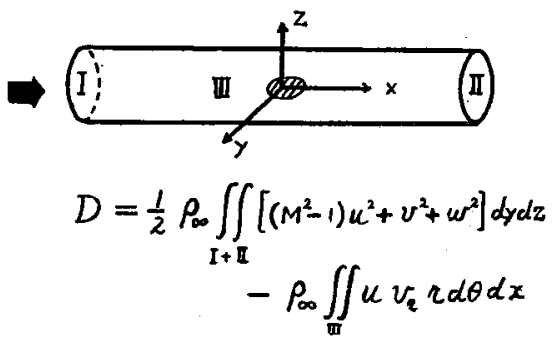

籍 5 図運動量調查面 と抵抗裴示式

ずれる $y z$ 面に度行とする. 円筒の半径 $\boldsymbol{r}$ が十分大き いときこの円筒の面を運動量の調笪面にとれば，物体

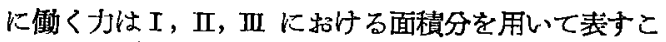
とができる、線型理論を適用し，かつ $x$ 方向の力すな わち抵抗Dゲけについて計算すればその表示は次の上 万になる。

$$
\begin{gathered}
D=\frac{1}{2} \rho_{\infty} \int_{\mathrm{I}+\mathrm{II}}\left[\left(M^{3}-1\right) u^{y}+v^{3}+w^{3}\right] d y d z \\
-\rho_{\infty} \iint_{\mathrm{III}} u v_{r} d \theta d x
\end{gathered}
$$

たゲし $r=\sqrt{y^{2}+z^{2}}, \theta=\tan ^{-1}(z / y), v$. は半径方 向の檩乱速度である。

さて，この抵抗の表示式は円筒が物体を完全に包え でいるが゙り円筒の大きさには無閣係であるから，面

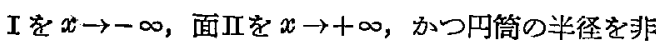
常に大きくとろう，無限前方には揣乱は及ばないから 右辺第 1 項の面 Iに関する皘分は答になることは明か である.このようにして物体の抵抗は二つの項から成 ることがわかった，この中右辺第 1 項すなわち面而の 積分上り生ずる抵抗を渦抵抗といい，第 2 項すなわち 
円筒面而の皘分より生ずる抵抗を造波抵抗と定義す る。

造波抵抗 $D_{W}$ は次の上万に害直される。

$$
D_{W}=\lim _{r \rightarrow \infty}\left(-\rho_{\infty} r \int_{\partial}^{2 \pi} d \theta \int_{-\infty}^{\infty} u v_{r} d x\right)
$$

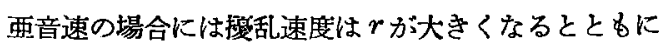
減宗し右辺の積分は零となる，乙たがって造波抵拫は 生じない．乙かしながら超音速の場合には大部分の摄 乱は物体加ら出る Mach 波の波面の近傍に集中され減 衰の程度も少ない，特に 2 次元物体の場合は線型近似 では擾乱は全然減衰しないで無限遠方まで伝わる。た 沉しその範围は物体から出る Mach 波面に集中され る. その結果超音速流では 2 次元物体でる 3 次元物体 でも一般に造波抵抗を生ずる.

次に前の式の右辺第 1 項に上って表わされる渦提抗 を $D_{\boldsymbol{V}}$ と据けば

$$
D_{V}=\frac{1}{2} \rho_{\infty} \iint_{-\infty}^{\infty}\left(v^{a}+w^{2}\right) d y d z
$$

と書ける．この調査面は物体の遥か下流に一様流に直 角に置かれたいわゆる Trefftz 面である.

理想流体中に括ける渦の保存を表した Helmholtz の定理は，圧縮性流体に招いてもるちろ九成立する。

したがって物体か場力を持つ場合にはその下流に自由 渦が流出乙，無限遠方の. Trefftz 面にまで及心゙. ᄂ たがって面内に检乱迶度成分 $(v, w)$ を誘導し，渦抵 抗 $D_{V}$ を生ずる，渦以外の㜔乱は物体からの距離とと るに減小し Trefftz 面までは及ばない。

物体から無限後方に拈ける流れに対しては後で述べ る slender-body の理論力゙適用でき，これを支配する 微分方程式は $\varphi_{x x}$ を省略して

$$
\varphi_{y v}+\varphi_{z z}=0
$$

となる.この式からかかるよらに Trefftz 面内の捡 乱は Mach 数に無関係な微分方程式によって表され る.このことから，もし渦度の分布が同一ならば渦抵 抗は Mach 数に無関係に同じ值をとるといらことがい える. 亲た当然の事ながら，揚力を持たぬ翼には渦抵 抗は生じない。

覀音速前緑をるった翼の抵抗を取圾了場合，特に注 意すべきことは前縁の吸引お（suction）でする。亜省 速的前縁に㧧いては流れの性質は定性的に亚音速流れ そ相似で岕って，迎角のある場合，線型理論ではここ に無限大の負圧を生ずることは既に述べたと括りであ る.このように無限小の半径をむった前縁に無限大の 負压が作用する結果，有限の吸引けが現われる。厚さ のない2 次元平板翼か㳡角 $\alpha$ で Mach 数 $M_{n}(<1)$
の亜音速流れの中に置かれた場合，前縁附近の正力は 前緣からの距離の $(-1 / 2)$ 乘に比例乙極限皘分の結果 前绿の単位長当りの負の抵抗 $D_{-}$は

$$
D_{-}=-\frac{2 \pi q_{n}}{\sqrt{1-M_{n}^{2}}} G
$$

となることは既によく知られている。ここで $g_{n}$ は野 圧， $G$ は常数である. 反りのない平板では圧力は面 に直角に作用するから，揚力 $L$ によってLaなる抵 抗を生ずる. したがって全抵抗 $D$ は

$$
D=L a+D_{-}
$$

と表される。一般に亜音速流では La と D 一 との絶 対值が等しくなり $D=0$ が成立する，これに反し超 音速流中に沶かれた翼の前緑が超音速的の場合は $D_{\text {一 }}$ $=0$ となる，覀音速に和ける上記の性質は，超音速に 括ける亜音速的前緑にすそのまま適用でるる，ただ， $D$ 一の計算に抬いて $q_{n} ， M_{n}$ として前緑に直角の速度 成分に関する值をとらなければならない，この結果， 前縁がすへて亜音速的であるよらな平面翼には造波抵 抗は生じない。

翼の下流に流出する自由渦の強さは翼幅方向の揚力 分布げけによってきまる，そして翼後緑か㯧音速的で あってる覀音速的であってもそれには無関保に流出す る.翼の渦担抗係数は，超音速においても亚音速の場合 と同様揚力保数の 2 乘に比例する.ただ超音速流では, 翼力揚力を持つことにより造波抵抗をる生じ，その你 数も末た揚力俰数の 2 乘に比例するので混乱を生じ易 いしかし実用的に見ればこれらの二つを吩離して計 算する必要のない場合が多く，揚力に上って生した造 波抵抗と瀜抵抗とを合せて䛾導抵抗と呼んでいる。

\section{4. 琵 理 論}

翼のような平面的な搪りを持った物体を取报ら場合 これを平面閣題と言 5 . 今翼の平面が $z=0$ の面に置 かれているすのと考えよ5，線型近低に対応する境界 条件は，峳堂な翼面上の条件をとる代りに，その点に おける翼面の勾配がその点の $z=0$ の面への写影点て

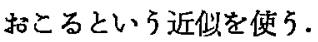

翼理論に小援乱法を応用する場合，翼は，迎角のな い対称翼，迎角をもった厚さのない平板翼，反りおよ び提りをもった曲面翼に分けて考え，それら括の和の が独立にあった場合の解を重的合壮て一般解を求める： のは非王緶流の場合と同栚である，曲面翼に対して はこれを平板翼素の集りと考えることができるから今 はこれを議論の対称から除くこととする.すなわち対 称翼と揚力面とを考えよ5.

この二つの場合に対して㹉乱ポテンシャル と摄乱 速度 $(u, v, w)$ との性䐝ををとめると次の表のよ5 
Кなる7).

\begin{tabular}{|c|c|c|c|c|c|}
\hline Case & $\varphi$ & $u$ & $y$ & $w$ & 物 \\
\hline 対攵 & $s$ & $s$ & $A$ & $s$ & 厚きのある対称显 \\
\hline 救力 & $A$ & $A$ & $s$ & $A$ & 迎角をるった将枚垌 \\
\hline
\end{tabular}

ここで $S$ は $z=0$ の面に対して対称， $A$ は非対称を 表す.ここに注意すべきは非対称性の隶数は翼面外の $z=0$ の面では零とならなければならないという性質 をあつことである.

超音速翼理論で最る一般的に用いられる方法は，再 音速の場合と同様に， source (sink)， doublet，むる いは vortex などの singularity を翼面に分布させ る方法である. $m$ なる㤝さの source その他の singularity 沾 $\left(x_{1}, y_{1}, z_{1}\right)$ k置かれた場合，これによ って点 $(x, y, z)$ に誘導されるボテンシャルは次の上 5に表される。

$$
\begin{aligned}
& \text { Source } \\
& \text { Doublet ( } z \text { 軸に平行な軸) } \frac{m}{2 \pi} \frac{\beta^{*}\left(z-z_{1}\right)}{r_{c}} \\
& \text { Elementary vortex }-\frac{m}{2 \pi} \frac{\left(z-z_{1}\right)\left(x-x_{1}\right)}{\left(y-y_{1}\right)^{2}+\left(z-z_{1}\right)^{2}} \frac{1}{r_{c}} \\
& r_{c}=\sqrt{\left(x-x_{1}\right)^{2}-\beta^{2}\left(\bar{y}-y_{1}\right)^{2}-\beta^{2}\left(z-z_{1}\right)^{2}} \\
& \beta=\sqrt{M^{2}-1}
\end{aligned}
$$

聥乱範囲は当然 singularity を頂点とする Mach 円 錐の内部に限定されるから，これらの式中の根宂の中 が負になることはない:ここに注意しなければならな いことは，基礎微分方程式は $\varphi$ のみならず，その微 係数すなわち $u ， v ｗ$ などよっても当然満足され るから，これらの表式は $u ， v ， w$ などに対しても成 立寸るととである.

翼面上に source を置くそいう仮定は，その点に拉 いて流れか涌出することを意味するすのであるから， source \&，その上下面に执いて速度 $w$ の不連続を生 じせさる.すなわち source を翼面上に分布させるこ とは， $\varphi$ と翼面上の $\Delta w$ ，とを結付けるるのである. 同梯に doublet 分布は $\varphi$ とA $\varphi$, vortex 分布は $\varphi$ と $\Delta p$ （あるいは $\Delta u ）$ とを関係付けるるのである. これ らの閶保式は次の上5になる.

$$
\begin{aligned}
& S: \varphi=-\frac{1}{2 \pi} \iint_{\tau} \frac{\left.\Delta w\left(x_{1}, y_{1}\right)\right)}{r_{c}} d x_{1} d y_{1}, \\
& D: \varphi=-\frac{2 \beta^{\mathrm{a}}}{2 \pi} \int_{\tau} d y_{1} f d x_{1} \frac{\Delta \varphi\left(x_{1}, y_{1}\right)}{r_{c}^{3}}
\end{aligned}
$$

$$
\begin{array}{r}
V: \varphi=\frac{U}{4 \pi} \iint_{\tau} \frac{z\left(x-x_{1}\right)}{\left[\left(y-y_{1}\right)^{2}+z^{\prime 2}\right] r_{c}} \\
\times \frac{\Delta p\left(x_{1}, y_{1}\right)}{1} d \rho_{\infty} d y_{1}
\end{array}
$$

ここで積分記号 $f$ Hadamard の有限部分 (finite part）を表し

$$
\frac{\partial}{\partial x} \int_{a}^{x} \frac{A(y)}{\sqrt{x-y}} d y=f_{a}^{x}-\frac{\partial}{\partial x} \frac{A(y)}{\sqrt{x-y}} d y
$$

で定義される $\left.{ }^{8}\right)$ ここで $て は$ 翼面中点 $(x, y, z) の$ 前方 Mach 円錐に含をれる部分を意味する，特に source の場合を計算すると， $z=0$ の面における $\Delta w$ $\left(x_{1}, y_{1}, 0\right)$ は同じ面内の他の点 $(x, y, 0)$ Kは $z$ 方 向の速度 $w$ を誘導しないととがわかる．したがって source 分布は前に示した対称翼の境界条件を满すこ とができる、これに対し doublet 招よび vortex 分布 は揚力面間題に応用される.

空気力学を取报 5 場合，問題の与え方に常に二種類 ある.第一は物体の形状を与六て圧力分布を求めるこ と，第二には圧力分布を与えて物体の形状を求めるこ そ，である. 空気力学では前者を direct problem, 後者を inverse problem とい5.さて，上の三つの 式を取报 弓場合， $\Delta w, \Delta \varphi, \Delta p$ などを既知㖤数として 与えられて $\varphi$ を求める問題と，その反対に $\varphi$ あるい はその碳係数， $1 ， v ， w$ なとを与えられて $\Delta w ， \Delta \varphi$, $\Delta p$ などを求める二つの場合が步る，挠者の場合は程 分方程式を解く事になり，前者より数学的团難务゙大き くなる. 数学的には前者を direct, 後者を inverse problem といち. 室気力学の問題では, 不幸にして後 者に帰着する場合が多い。しかし困難な inverse problem もある場合には direct problem に变換する ことができるしまた既に知られている elementary な 解を重权合せて複雑な問題を解く事ができる場合が多 い. 以下簡単な例に上ってその取扱い方の一端を示す こととする.

第6図に示すのは流れに正対する矩形翼である，破

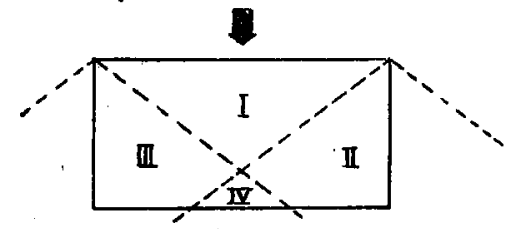

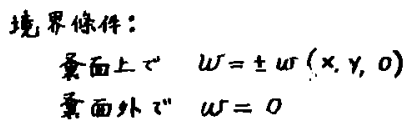

第 6 図 矩形巽（迎的管） 
線で示したのは両翼端から出る Mach 冈雓と $z=0$ の 面の卒線である、この線によってこの翼面は IからIV までの 4 つの部分に䂆けられる。. I は耐翼端の影響を 受けない部分で，ここでは流れは翼幅の無限に大きい 場合，すなわち 2 次元の場合と全く同様である。II招 よび円゙ はそれぞれ右翼端扣よび左翼端の影響を蒙る 範囲，IVは両翼端见影響される部分である.

さて最初にこの翼か肉厚だけを持った対称翼の場合 を考它よ5，境界条件は図に示した如く翼上下面で $w= \pm w(x, y, 0)$, 翼面外 $z=0$ では奶称の条件か ら $w=0$ でなければならない.このよ5な流れの性 質は，既に述べた如く翼面上に source を分布させる 事によって満足させることができる・この場合 source 分布の式からわかるように被皘分函数が $\Delta w$ で既知で あるからこれを解くのに何ら数学的团難性伴わない。

これに反し同じ平面形をるった迎角する平板の場合 はやや状況が異なる. 第7 図结半無限長短形翼の翼端 を示す．迎角をるった平板翼と考穴上5，境界条件々 して翼上下面で $w=w_{0}=-\alpha U$ が与えられ，翼面上 の $\Delta p$ を求める問題である. 既に述べた doublet ま るいは vortex 分布の場合の $\varphi$ と $\Delta \varphi$ 岁るいは $\Delta p$ との関係式から微分によって $w$ と $\Delta p$ の関係を求め, これから直接解を求める事は不可能ではないが，この 方法では inverse problem となり数学的困難が多く なる.

これを避けるためにとられた一つの方法は次の需ね 合せの方法である. 今下の図の上5に $y=m x$ といら

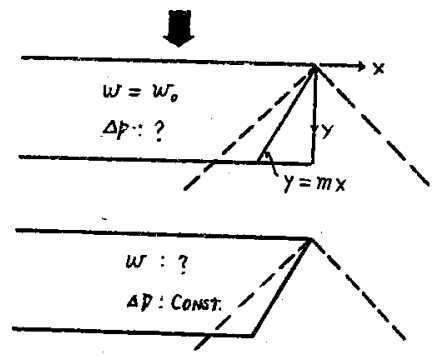

第7図迎危をるつた矩形翼

辺を持つた梯形翼を考光，これが全翼面にわたって一 定の揚力をるっすの仮定する。したがつてこの翼の 璄界条件は $\Delta p$ が既知で， $w$ が末知となる. この問題 は direct problem として簡単に解く事ができる. 乙 たがってての翼による吹下し $\delta w(x, y, 0)$ は $\Delta p(m)$ の函数となる． $m$ の異なる多くの梯形翼を考えてこ れらを加え合せ結局翼面上でそれらの各翼素比よる吹 下し $w$ が $-\alpha U$ と一致するよ5に各翼素の受持つ負 倚を決定する，最後は䅡分方程式となるが，その解は 比較的闲難なしに求めることができる。
同じ問題に対する他の方法はいわゆる揚力打消法と 浮ばれるるのである. 第8図に执いて(1)は 2 次元平 板翼である. 迎角 $\boldsymbol{\alpha}$ のために翼面上では $w=-U_{\alpha}$ 負荷 $\Delta p$ はその図中に書迈んゲような一定値をとる.

(1)

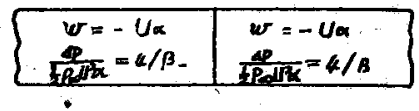

(2)

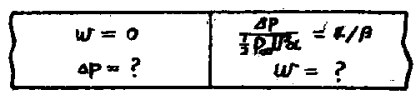

(3)

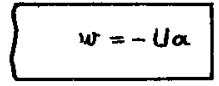

第8図揚力打消法に腹いられる境界条件

翼 (2) は平面形は (1) と同じで, 中心から右側ては $\Delta p$ を 2 次元翼と同しに与六, 左側の部分で $w=0$ そ いら条件が与充られるものとする. 右侧翼付するポ テンシャルは $\Delta p$ が与えられているから簡単に求京

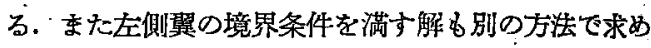
られる. 結局翼 (2) の解は比較的容易に求められる. そして翼 (1) と翼 (2) の解の差をとれば. 翼 (3)， すなわち半無限平板矩形翼の迎角 $\alpha$ の特の解力救め られる.

上上揚力をすつ平板矩形翼の場合について二つの例 を示したが，その他にも多くの方法がある. そのうち 最も強力で応用の広いものは Busemann によって創 められた錐場理諭である。

\section{5. 錐場理論 (Conical-Field Theory)}

第 9 図の上らに，半無限長の錐状物体力頂点を先に して超音速流れの中に置汃れた場合を考えよ5．頂点 からMach 波加出る が，線型近似の範囲 では, この波面は $x$ 軸を軸とした完全な 冈錐となる，境界条 件は Mach 円錐の上 て接乱が零というこ とと，流れが物体面

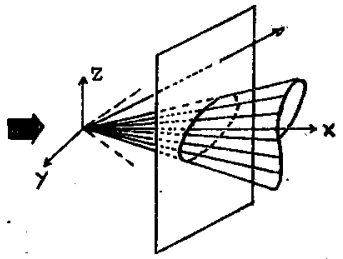

第 9 図 踓場の流れ に沿って流れるといら事である。したがって，むし頂 点から弓いた半值線の上で速度, 压力, 密度など流れ の变数が一定であるような流れか存在すればての流れ は与えられた境界条件を滿与。この上らな性質を持 ち，加基礎微分方程式を満足する流れは実際に存在 乙，乡の理論学錐場理論とい5。この理論は線型化し ない厳筫な微分方程式に対して成立し，頂点から衝 慗波の出るよらな場合にも適用する事ができるが，こ こでは線型化された錐場理論についてだけ述べる. 
超音速流の線型微分方程式

$$
\left(M^{2}-1\right) \varphi_{z: x}-\varphi_{y y}-\varphi_{z z}=0
$$

は Prandtl-Glauert 変換

$$
x_{1}=\frac{x}{\sqrt{M^{2}-1}}, \quad x_{2}=y, \quad x_{3}=z
$$

によって波動方程式

$$
\varphi_{x_{1} x_{1}}-\varphi_{x_{2} x_{2}}-\varphi_{x_{3} x_{3}}=0
$$

となる。

$X_{2}=x_{2} / x_{1}, X_{3}=x_{3} / x_{1}$ と招き $\varphi$ が $X_{2}, X_{3}$ 沈けの函. 数と仮定すると微分方程式は

$$
\begin{aligned}
& {\left[1-X_{2}^{2}\right] \frac{\partial^{2} \varphi}{\partial X_{2}^{2}}-2 X_{2} X_{3} \frac{\partial^{2} \varphi}{\partial X_{2} \partial X_{3}}+\left[1-X_{3}^{2}\right] \frac{\partial^{2} \varphi}{\partial X_{3}^{2}}} \\
& -2 X_{2} \frac{\partial \varphi}{\partial X_{2}}-2 X_{3} \frac{\partial \varphi}{\partial X_{3}}=0
\end{aligned}
$$

となる.

更K $\theta=\tan ^{-1}\left(X_{2} / X_{3}\right), r=\sqrt{X_{2}^{2}+X_{3}^{2}}$ なる極座 標を用い，次いで Tschaplygin の变換

$$
\theta=\theta, R=\frac{1-\sqrt{1-r}}{r}
$$

を使うと，微分方程式は次のよ5に書ける。

$$
\varphi_{R B}+\frac{1}{R} \varphi_{R}+\frac{1}{R^{2}} \varphi_{\theta \theta}=0
$$

この式は Laplace の微分方程式である.

・この方程式は単にボテンジャルののみらずその微

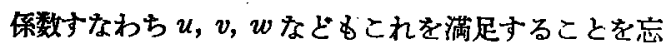
れてはならない，実際の錐場理諭に扎いてはポテンシ

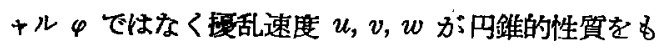
つものと考える.さて，以上の変換を $X_{2} X_{3}$ 面で考元 ると, Mach 円錐の切口の半径がちょ 5 ど 1 kなるよ らな 軸に垂直な面内の，Mach 円と物体の間にある 流れを規定するすのと考元られる：また Tschaplygin 变換によってる Mach 网は半径 1 の円に保たれる.

今得られた基焚方程式は Laplace の方程式である から，われわれは複素函数とい5強力な数学的武器を 駆使して問題を解く事ができる.

第10这に示したのは半無限に搪がった矩形翼であ る. 翼端からの Mach 円錐の半径が 1 になるような $A$ A断面を考えよ5，下図左は対称翼の場合である，境 界は翼，翼端から出る Mach 円錐，拉よび前縁から上 下K伸びる Mach 波の切口で与えられる. Mach 円錐 上挌よひ翼面上の境界条件は図に示す如くである，境 界条件がすへてていのみで与えられることに注意する必 要がある.このよらな境界条件を㴖しかつ $w$ に関寸

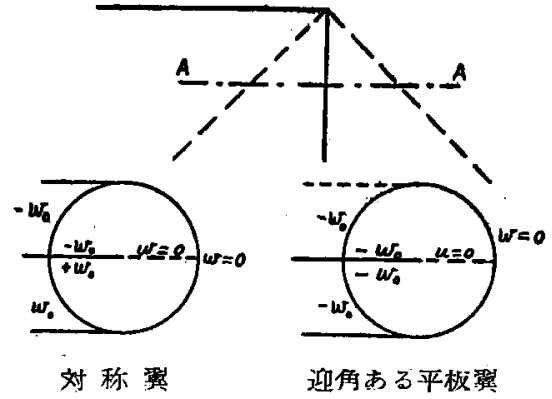

第 10 図 矩形翼端の境界条件

る Laplace の微分方程式を満足する解を求めること は梅素函数を用いればそれ汪ど困難でない。

同図下右は場力面の場合である．この場合， $z=0$ の 面に括いて翼面の外では $w$ は未定でその代り $x$ 方向 の速度 $u$ の非刘称性から $u=0$ とい5条件が与えら れる. したがって単一でない湿合した境界条件にな り，やや複栋となるが，これる Busemann によって conjugate function を考えることKよって解決され t.

次にこの例題において，翼を超音速的後緑で切取っ ててま5ものと考えよう．この場合後緑の後の領域で は， $z=0$ 面で対称翼の場合は $w$ か零になり，揚力面 の場合は $u$ カ零とならなければならない.したがつ てそのよ5な境界条件を满すために後縁から後の部分 に何らかの singularity を分布させなりればならな い. しかしこれらの singularity は超音速的後縁の下 流にあるからそれより上流には何らの影響る及ぼし得 ない，結局今求めた錐場の解はこの上うな有限翼弦の 場合にす何らの修正なしに適用できる。

錐場理論の適用範囲は非常に広く，むし万超音速翼 理論の主流をなしているといってもいいぐらいであ る. また単に平面閣題でけではなく雓状の物体に対し て広く応用されていることはるちろんである。

\section{6. 細長い物体の理論(Slender-Body .Theory)}

物体の形状が $y, z$ 方向の变化に対して $x$ 方向の变 化が小さいような場合には slender-body の理論が適

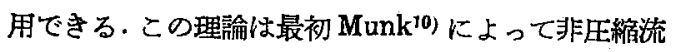
における飛行船の場合に応用され，後 Jones'i1)に上 って綖横比の小さい翼に应張された. 超音速では翼の aspect ratio は小さくなり slender-body の条件を満 す物体を取扱 5 場合が多く，この理論の活躍範国は非 常に広くなった。

基璴方程式

$$
\left(M^{2}-1\right) \varphi_{x x z}-\varphi_{y y}-\varphi_{z z}=0
$$

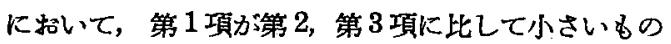


と仮管すれば

$$
\varphi_{y y}+\varphi_{z z}=0
$$

が得られる，上の仮定は物体の長さを $l$ ，幅を $s$ とし た㭙表面が滑かな物体に対して $\left|\left(1-M^{2}\right)\left(s^{2} / l^{2}\right)\right|$ が 1 より非常に小さい場合に成立つ，この slenderness の 仮定はあくをで物体の近傍だけで成立つむのであつ $て$ ，物体から遠く離れた所には適用し得ないものであ ることは特に注意しなければならない。

$$
\varphi_{y y}+\varphi_{z z}=0
$$

が slender-body に対する基碟方程式となるがっこの 式から明かなよらに， slender-body では流れに面角

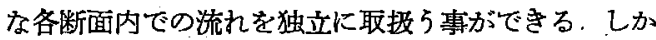
すその括の抬のの流れを規定する方程式は最も簡単な Laplace の方程式である. すなわち各断面に打ける非 壬縮流れを求め，これをつなぎ合せれば slender-body 周りの流れを決定をきる、特に注意を要する事は，こ の微分方程式が $M$ を合まない事, したがって slenderbody の理論は slenderness の仮定さえ满されていれ ば，超音速，亜音速の別なく適用できることである.第 くべきことは，線型方程式が妥当性を失 においても少くる厚さのない翼に対してはこの理論が 成立する事である12．そのためこの理論は高速空気的 学に执いて非常に大きい価值をもっているのである.

\section{上の微分方程式の一般解は}

$$
\varphi(x, y, z)=\varphi_{1}(y, z ; x)+g(x)
$$

で表される、ここで $\varphi_{1}$ 中に含をれる $x$ は物体の境界 が $x$ 方向に変るため parameter として含まれるもの である，本た $g(x)$ は $x$ の任意函数である， $y h(x)$ ， $z k(x)$ の上5な項が合机ないことは別の方法で証明 できる. 特に揚力面を报万場合には $\varphi$ は $z=0$ の面 に対して非対称でなければならないから $g(x)=0$ と なる。

圧方と速度との関俰はこの理碥では特に注意しなけ ればならない，何故ならば， $\varphi_{x}$ に対して $\varphi_{y}, \varphi_{x}$ が きくなるからである。この近似に於ては圧力は

$$
\begin{aligned}
p & =-\rho_{\infty} U \varphi_{\varphi_{x}} \text { planar body } \\
& =-\rho_{\infty}\left[U \varphi_{\infty}+\frac{1}{2}\left(\varphi_{y}{ }^{2}+\varphi_{2}^{2}\right)\right] \text { non-planar body }
\end{aligned}
$$

で表される.

この理論の適用例を第 11 図に示した三角平板翼の 揚力閣題について説明する. Aspect ratio の小さい三 角翼が $a$ なる迎肩で流れに正対しているるのとする。 これに slender-body の理端を適用して図のAA 断面 を考劣る，この断面内の流れは，幅 bなる板に㨁角下

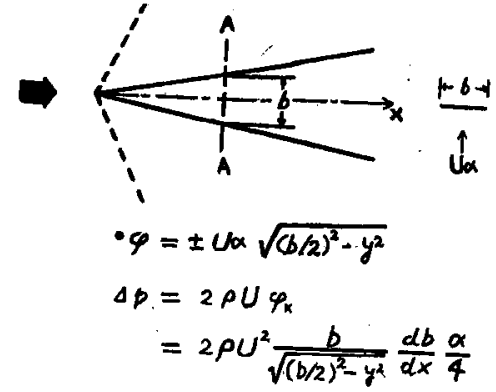

第 11 図 小さい綎横比の三盾翼とその負荷分布

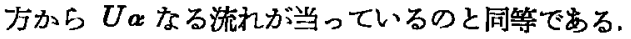

この境界条件と Laplace の微分方程式を滿す解性， 簡単に求められ，既によく知られているよ5にに $z=0$ おけるポテンシャル $\varphi$ の不連続

$$
\varphi= \pm U \alpha \sqrt{(b / 2)^{2}-y^{2}}
$$

を生ずる．したがって上下面の生力差は

$$
\begin{aligned}
\Delta p & =2 \rho_{\infty} U \varphi_{\varphi_{x}} . \\
& =2 \rho_{\infty} U^{2} \frac{b}{\sqrt{(b / 2)^{2}-y^{2}}} \frac{d b}{d x} \quad \alpha
\end{aligned}
$$

となる，すなわち負荷は $d b / d x$ に比例する， $\Delta p の x$ についての積分は翼幅方向の揚力分布を与える.すな わち

$$
\frac{\partial L}{\partial y}=\int \Delta p d x=2 \rho_{\infty} U_{\varphi}
$$

$\varphi$ は棈円形であるから揚力分布も楕円形となり誘導 抵抗は最小となる.揚力は

$$
L=\frac{\pi}{4} \rho_{\infty} U^{2} a b_{M A X}
$$

となり，翼の平面形に関保なく最大幅によって決定さ れる. 誘導担抗は非圧縮流れに括ける表示式をそのま ま使つて

$$
D_{i}=L^{2} /\left(\pi q b^{2} M A X\right)
$$

と表される. 倸数の形に值すと

$$
\begin{aligned}
& C_{L}=\frac{\pi}{2} \cdot A \alpha, \\
& C_{D t}=C_{L} \frac{a}{2}
\end{aligned}
$$

となり揚力は翼面の垂值方向と $z$ 万向とのちょらど中 間の方向をもつ.

以上の結果は雓場理論から求めた三角平板望の aspect ratio を零にした極限の場合に一致する，平面形 が最大幅をもっているよ5な場合は，その下流の终榇 から渦が流出し，この渦に上る吹下しのために最大幅 
の断面より後にある翼面は揚力を持たないことが結論 できる.

この理論は aspect ratio の小さい翼に対してばか りでなく，胴体と翼の組合せの上5な椱雅な境界条件 をるった場合にも適用されていい結果を与光る，特に 亜音速から逶音速を通って超音速領域にまで少くも揚 カについて一様に適用性のあることはこの理論の非常 な強味である。

\section{7. 䟿型理論と実娩との此較}

'以上K沶いて，超音速線型理論の大要を説明した。 この章に䋆いて線型理論と実験との比較を行う．

第 12 区は，10\%の厚さを持った 2 次元円弧翼が 10

NACA の許可溫

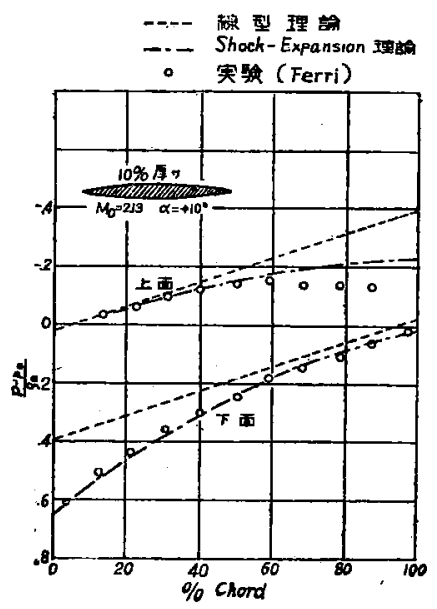

第 12 図 奶称円孤翼の圧力分布

度の迎角で $M=2.13$ とい5 Mach 数の流れの中に 置かれた場合の圧力分布を示す14)．破線で示したのが 線型理論に上る計算値で，円弧翼の場合圧力分布は直 線になる. 丸印は Ferri の実験結果である，同図に は Busemann の shock-expansion 法に上る值と特 性曲線法による値とが畫加えてある. 線型理論と実験 值とは，上面では後半部で，また下面では前半部で喰 違いが大きくっている，その理由は線型理論では㣫 慗波を正しく取扱ら事ができないのと，境界層の剥離 のためでする. Busemann の理諭扣よび㛜峾理論は, 流れの剥離を生ずる上面約 $60 \%$ 翼弦長以下の部分を 除いては実験とよく一數する，乙かしながら，圧力分 布の積分值すなわち揚力をとると線型理論による值は 实験値とかなりよく一教することは同図の曲線の傾向 を眺めればすぐわかる，この上らな事実は他の場合に るしばしば現われ，線型理論の価值をますます高くし ている. この場合モーメンント保数 $C_{m}$ 恃压力分布に関 係するから線型理論と央験との绘逶は大きくなる。こ
こで注意を曼起したいことは，本実験の翼厚 $10 \%$ ，迎 角 10 度といら条件は線型理論にとってははなばで諧 酷なあのであるといらことである.

第 13 図に示したものは，剓形翼上の一点に扣ける

NACA の許可済

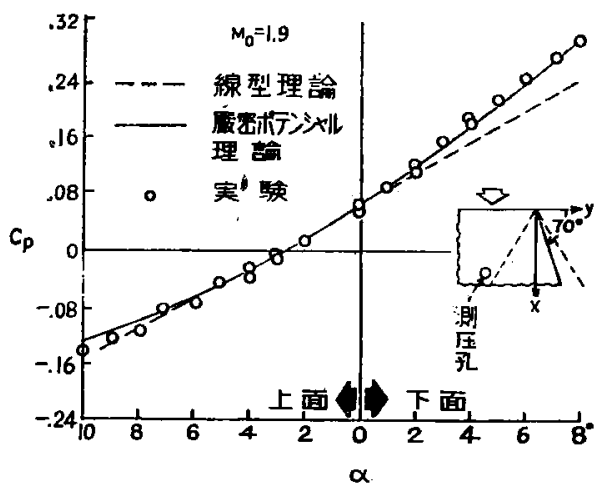

第 13 図梯型翼翼端に扎ける压力保数

壬力係数と迎角との関倸で，Mach 数は 1.9 である ${ }^{13)}$ 測定点は翼端 Mach 冈錐の外側に步るから，この点の 流れは 2 次元的性格をもっている。破線は線型理論に よる值を示し，これと実験結果とは約 8 度の迎角範囲 にわたって良好である.

第 14 図は同じ翼の翼端 Mach 円錐内に含をれる点 NACA の許可济

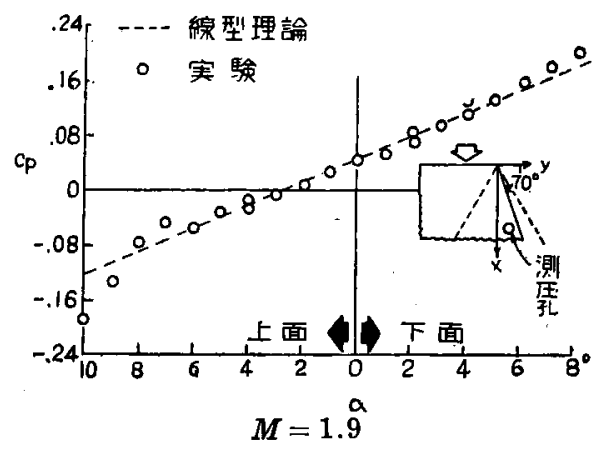

第 14 図 梯形翼翼端に括ける圧力保数

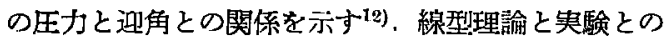
一致は前の場合より更に良好であり，その迎角範囲も より広くなっている。

第 15 図は Mach 数 1.49 の流れの中に怙かれた三 角翼の揚力分布について理諭と実験とを比較したもの である13)，翼は厚さ $6 \%$ の円弧翼の前緑を丸めたるの で 70 度の後退角を持つ，図比示す 2 力所の断面に扣 いて㹎弦方向の負荷分布の理踰值と央験值とを迎角 $2^{\circ}, 4^{\circ}, 6^{\circ}$ の場合について示した. 耐者の一致は大体 艮好である，ただし更に外側の断面では前緑剚推のた めに deviation がひどくなる傾向を持つ. 
NACA の許可済

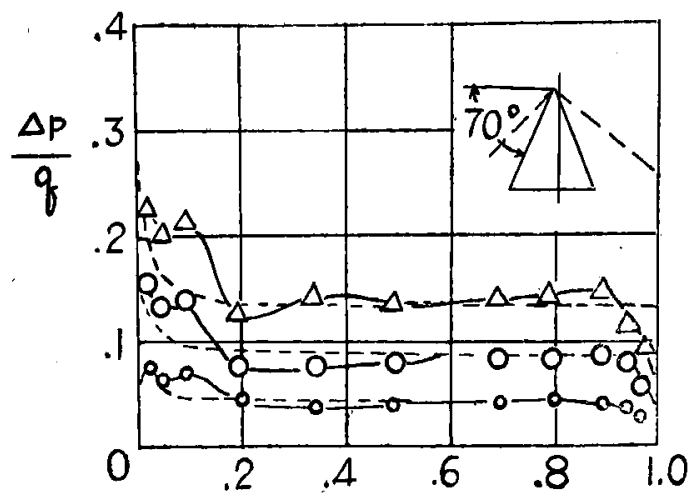

前

後

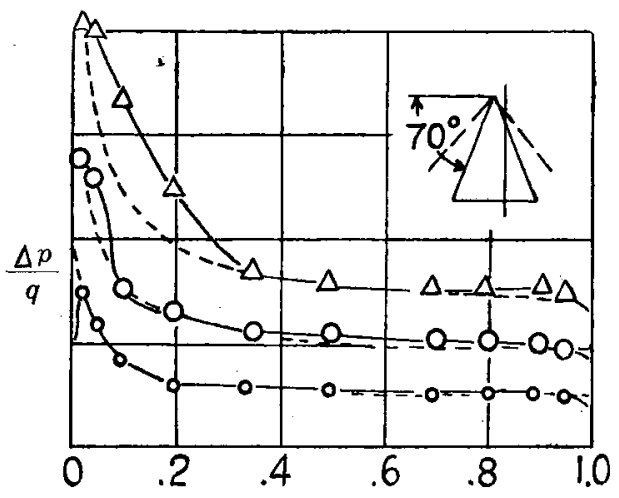

前

後

縟

緣

$$
M=1.49
$$

第 15 図 三角翼の翼弦方向負荷分有

第 16 図は前と同じ翼について翼幅方向の負荷分布 を示したるのである ${ }^{13)}$ ． また右上の图はこの負荷分布 を皘分して $C_{L} \sim a$ 曲線を求めたるのである，負荷分 布に打ける理論と奏験の墖違いは正負打消し合って $C_{L} \sim \alpha$ 曲線には現れて来ない，そのため $C_{L}$ に対して は線型理論の適用範囲か昿くなって来るのは與味深い ことである.

第 17 図は幾つかの後退翼扣上び前進翼の揚力傾斜

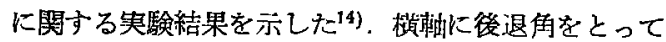
岁る，实験した Mach 数は 1.53 である 破線は理論

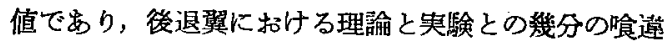
いは多分翼の剛性の不足に上って生じたものと思われ る.この図においては，線型理論と実験との一致か浪 好であるといら事实の他に，その曲線の対称性に注意 されたい，この実験では，前進翼は後退翼をそのまま 逆间きにして使ったもので軎る。
NACA の許可済

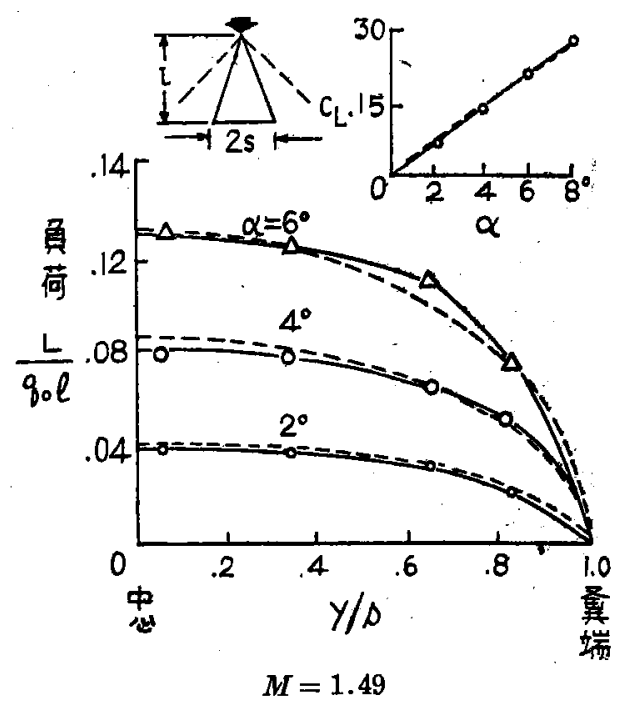

第 16 图 三角翼の負街分布

NACA の許可済

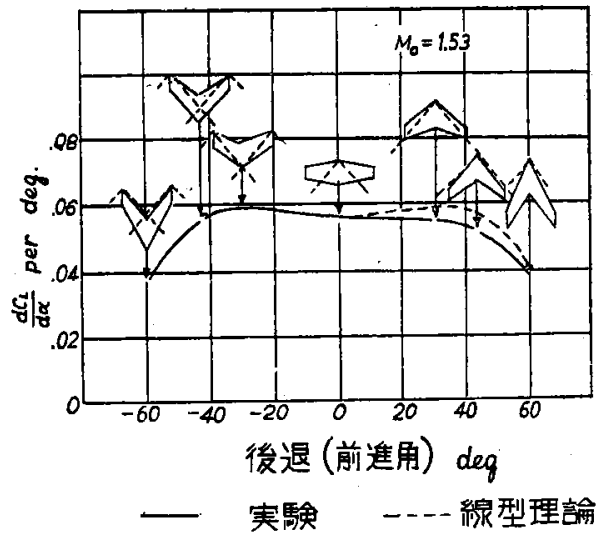

第 17 図 揚力傾斜に対する後退角の影望

弾性力学に执いて，片持梁を考え， $A$ 点に $F$ なる力 を作用した時 $B$ 点に生ずる変位を $D$ とし，逆隹 $B$ 点 に吕なる力を加えた時に生ずる $A$ 点の変位を $\bar{D}$ とする と,

$$
F(A) \bar{D}(A)=\bar{F}(B) D(B)
$$

なる関係娍立つことはよく知られている。

空気力学に颃いても同様な定理が成立する. 翼があ るMach 数で飛行している時, 翼面上の $A$ 点に $\delta p$ な る珐力が作用したために $B$ 点にWななる吹下しが生じ たとする.この翼を逆向きに同じMach 数で飛行させ

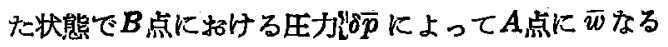
吹下しを生ずるものとすると，これらの閒には

$$
\iint \delta p(A) \bar{w}(A) d S=-\iint \delta \bar{p}(B) w(B) d S
$$


なる関俰が成立する．これを逆転定理といいるちろん 線型理論に捛いてのみ成立することでする

この定理を応用することによって央際の計算の手間 をはぶく事が

できる・第 18

図平板三角

翼の超音速に

批る揚力分

布を示すもの

で, 頂点を前

にして進む場

合を英線，後

にして進む場

合を鎖線で表

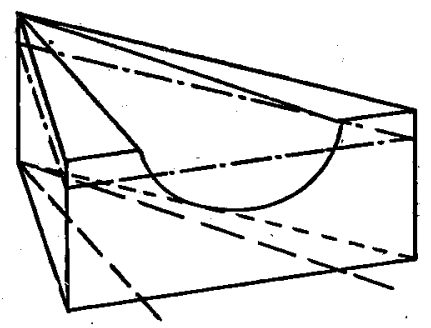

$$
\begin{aligned}
& \text { 整掦力对稻真： } D_{1}=D_{2}
\end{aligned}
$$

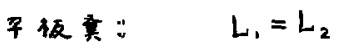

第 18 図 平板三角翼の負荷分布

してるる.この上うに翼面上の局部的な埸力分布は二 つの場合異なるが，その皘分値すなわち揚力自身は一 致する。

第 17 図に㞍って，最る左侧の翼は計算が複椎なた め現在理論結果は求められていない. 乙か乙揚力倾斜 に関する限り最右端の翼の計算からこの定理を使って 值を求めることができる．この定理は抵抗にも使宇 る. 第19図はこれらの翼の最小抵抗関するもので ある ${ }^{14)}$. 抵抗の場合は理論から子言される造波抵抗以 外に摩擦抵抗が入るので央験と理論の一致は悪くな る.

NACA の許可済

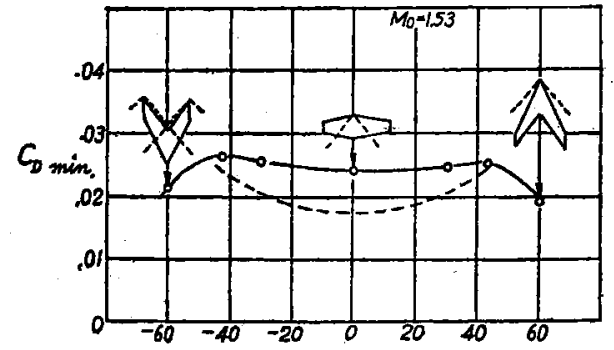

後退(前僬) 角 (deg)

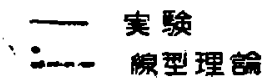

第 19 図 $C_{D \text { nin }}$ K対する後退角の影響

第 20 図は slender-body の理論と英験との比較を示 したすのでる゙リ. 模型は幅 $1 \frac{1}{2}$ in, 長さ 4 in の三 角翼で aspect ratio は 0.75 である. 英験 Mach 数 は 1.75 である. 図に $C_{L}$ そ $C_{m}$ について slenderbody の理論による値と央験結果とを示したが両者の 一致は $\pm 2^{\circ}$ 程度の迎角籍囲に括いて良好である.

Slender-body の理論恃胴体と基の組合にる適用で きるととは既に述へたが，第21图はその一例です
NACA 的許可済

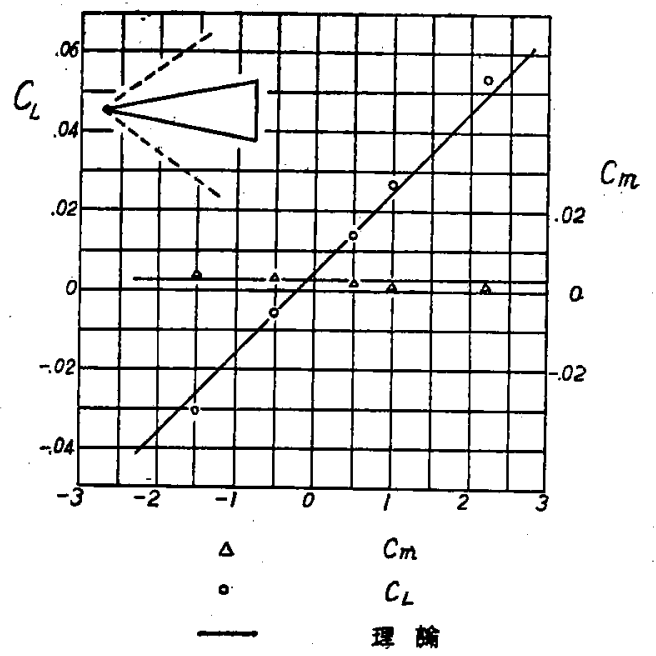

第20図三解翼に対する Slender-Body 理論 そ。 実験との比較

NACA の許可淥

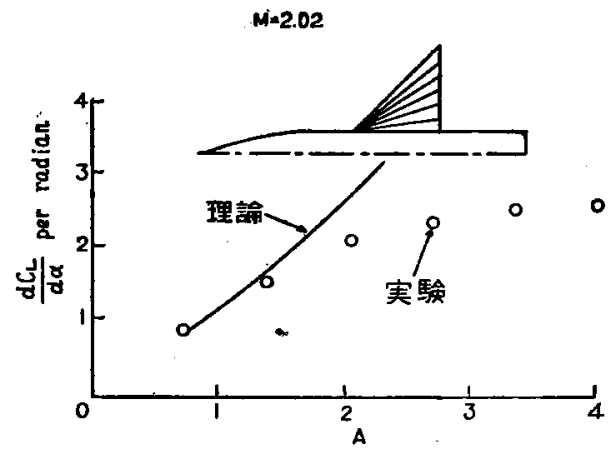

第21図巽挏体の粗合せに対する゙Slender-Body 理鯩 $と$ 実臨 $と の$ 比較

る15)。図に示すよらな模型について翼の aspect ratio を变えた場合の揚力傾斜を求めてある. 実線は理諭值 を示すが, 実験との一致は 1.5 程淁の aspect ratio で良好である。

以上各種の比較によって超音速楾型理論は十分英用 に供乙得ることは明かであうう。

\section{絬 言}

結びとして，本諭文においては線型理論を中心とし て超音速翼理諭の概要を説明し終りにその実用性を検 討する意味で笑験との比較について述べた. 限られた 紙面のために個々の翼の空気力学的特性, 抵抗娍小 法，翼，䏱体の組合せに関する問題，periodic motion なとにふれることのできなかったのは遺䧕である.

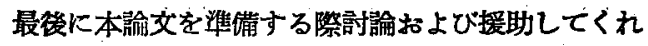
たことに対し理工研小口，村㥓両君に感謝する次第て 
ある. また図面の幾つかは米国 N.A.C. A.の出版物 より再製したすのであり，それらの掲載を快よく許可 してくれた N. A. C. A. 当局の好意に対しここに厚く 感謝の意を表するるのである.

\section{文献}

超音速理論の苓考交献に関しては，Th．von Kármán: Supersonic Aerodynamies-Principles and Applications, Jour. Aero. Sci., Vol. 14, No. 7, pp. 373-402，1947，にほとんど完全なりストが揭載さ れて括り，またその後の新しい交献をも含めて，M.

A. Heaslet and H. Lomax: Supersonic and Transonic Small Perturbation Theory, High Speed Aerodynamics and Jet Propulsion, Vol. VI, General Theory of High Speed Aerodynamics (Ed., W. R. Sears) pp. 340-344, に代表的な文献が揭载さ れている.ここでは紙面の都合上 Bibliography は上 の二つに変り，本論交中に引用した交献のみを挙げる こととする.

1) Ackeret, J., Luftkraefte auf Fluegel die mit groesserer als Schallgeschwindigkeit bewegr werden, Z. F. M., Vol. 16, pp. 72.74, 1925.

2) von Kármân, T. and Moore, N. B., The Resistance of Slender Bodies Moving with Supersonic Velocities with Special Reference to Projectiles, Trans, A, S. M. E, Vol. 54, pp. 333-310, 1932.

3) Schlichting, H., Tragfluegeltheorie bei Ueberschallgeschwindigkeir, Jabrbuch 1931 der Deutschen Luftfahrtforschung, pp. 181-197.

“熱の障壁”についてのシンボジウム：Symposium on the Thermal Barrier, A.S.M. E. Publication, New York, 1954 年, ii+72 面.

ASME の航空部門では，11月 28 日から 12 月 3 日 にわたった 1954 年の年会に拈いて，“熱の障壁”につ いてのシンポジウムを行った，シンボジウム自体は 2 日間にわたり，第1日午前は推進装置に対する問題 が，午後は䋃装とか附属品の問題が，第 2 日午前は機 体構造の問題が取披われた，それぞれ三つずつの講淀 が行われたよ5で, 本書はこれらの合計九つの講演を まとめたものである. 各講演には文献を添えて岁り， 癸行機の高速化の行手に立塞がる “熱の障壁” の問題 を見渡たす手頃な資料といえよ5，講演者と講演題目 は次のとおり：

第 1 部門ではずライト動力研究所の A.J.Gardner が，“超音速飛行用ターボ・ジェット・エンジンの薙 的問題への序諞” と題し，ビのぐらいの温度になる か，等源はどこか，設計に対する条件はどのようなる のかなどを論ずる．次は同じくライト動力研究所の R. B. Keusch の “動力装置系統に対する超音速飛行 の影響”で，燃料梁統，冷却系統，潤滑系統その他を 合めた野力装置系統の問題を扱い，最後に NACA の C. H. McLellan カ5 “空力的発熱に上る物体の融解”
4) Busemann, A., Infinitesimute kegelige Uebersehallatroemung (Infinitesimal Conical Supersonic Flow). N. A. C. A., T. M. $1100,1947$.

5) 代表的な利 $こ し \tau$, Pucketr, A. E., Supersonic Wave Drag of Thin Airfoils, Jour. Aers. Sci., Vol. 13, No. 9, pp. $475484,1946$.

6) 化表的株乏して, Lighthill, M. J., Supersonic Flow Past Slender Bodies of Revolution the Slope of whose Meridian Section is Discontinuous, Quart. Jour. Mech. and Appl. Math., Vol. 1, Pt. 1, pp. 90-102, 1948.

7) 前記 Busemann の論交の外すぐれた解璄モして, Lagerstrom, P. A., Linearized Supersonic Theory of Conical Wings, N. A. C. A. T. N. 1685,1953 .

8) 前䩕 W. R. Sears $の$ Text Book, pp. 229-235 参照

9) Adams, M. C. and Sears, W. R., Slender-Body TheoryReview and Extension, Jour. Aers. Sci., Vol. 29. No. 2, pp. 85-98, 1953.

10) Munk, M. M., The Aerodynamic Forces on Airship Hulls, N. A. C. A.'Report 184, 1924.

II) Jones, R. T., Properties of Low-Aspect-Ratio Pointed Wings at Speeds Below and Above the speed of Sound, N. A. C. A. Report 835, 1946.

12) Spreiter, J. R., Theoretical and Experimental Analysis of Transonic Flow Fields, N. A. C. A. -University Conference, 1954, pp. 18-1-18-17.

-13) Heaslet, M. A., Theoretical and Experinental Analysis of Some Supersonic Flow Fields, N.A.C.A. -University Conference, 1954, pp. 15-1-15-13.

14) Vincenti, W. G., Comparison between Theory and Experiment for Wings at Supersonic Speeds, N.A.C.A. Report 1033, $19 \overline{3} 1$.

15) Heaslet, M. A. and Spreiter, J. R., Reciprocity Relations in Aerodyamics, N. A. C. A. Report, 1119, 1953.

16) Nielsen, J. N., Aerodynamics of Airfoils and Bodies in Combination at Supersonic Speeds, N. A. C. A.-University Conference, 1954, pp. 16 $1-16-12$.

\section{評。}

と題し，空打的発熱による敳解の理論と央験結果とを 述べている. マッ八数は 6.9 あたりである。

第 2 部門には，ダダラスの主任設訫者 H.W.Adams の“高速機の備装に抽温度の問題”, フェアチャイ ルドの J. Makowski と V. L. Whitney 共同の“超音 速機に打る人体と備品との冷却”, 最媵にハーバー ド爷衆衡生学校の R. A. McFarland の“高速なら びに高空飛行に関連した人体の問題” が載せてまる. McFarland のものは䓡の間題に限らず高空ならびに 高速に伴 5 航空医学全般にわたっていて，特に人体と 機械との全体梁という考え方は與味深い。

第 3 部門は，ブルックリン理工科大学の N. J. Hoff

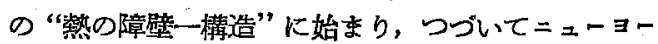
ク大学の G. Gerard の “熱を無視できない我行にお ける構造の諸問題”, ロッキードの F. R. Steinbacher と L. Youug 共同の“高温にさらされる飛行機. の設計に扔ける問題”がのっている. Hoff は警炕力 からはじめて䍌によるバックリングとかクリープを真 正面から碖じているだけだが，Gerard は䓡のために 弱くなる材料を使らことに伴う必然的な量量增加を特 に分析していて注目に值する. Steinbacher そYoung とのは荷重計算や安全率の取り方に対する注意であ る. (新羅一郎) 